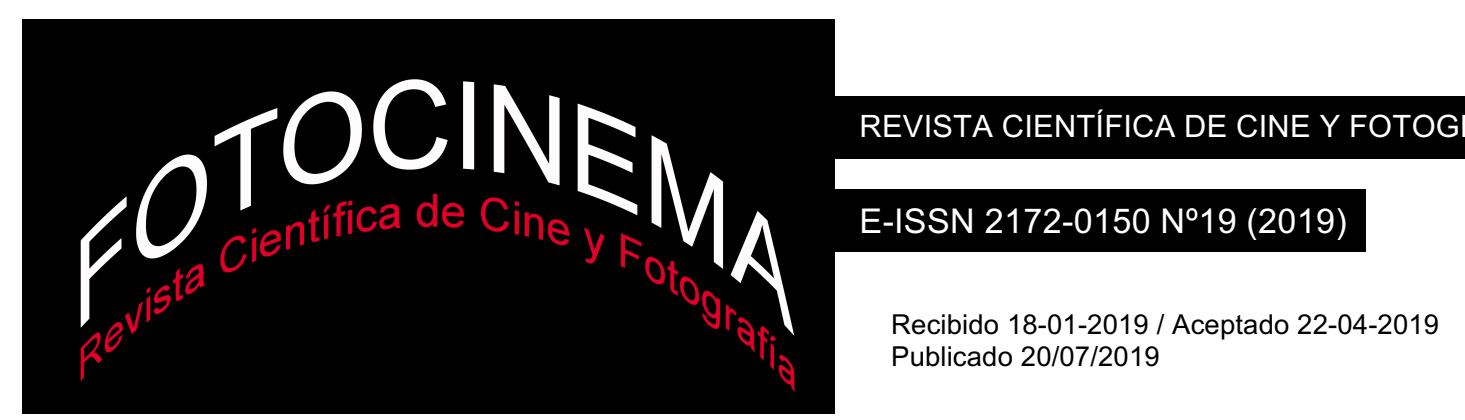

\title{
Romanticismo y antirromanticismo en La La Land
}

\section{Romanticism and anti-romanticism in La La Land}

\author{
Emilio José Álvarez Castaño \\ Zhejiang Yuexiu University of Foreign Languages, China \\ telemilio@yahoo.es
}

\section{Resumen}

Dentro de su clasificación genérica, La La Land fue etiquetada como musical romántico. Aunque no hay duda de que se trata de un musical, el artículo pretende reflexionar sobre su consideración como obra romántica, ya que también se pueden encontrar rasgos antirrománticos dentro del contexto postmoderno en el que fue creada. Para ello, se hará una introducción a los conceptos de Romanticismo y antirromanticismo y luego se abordará el estudio de la película desde tres ángulos distintos que parecen convivir en ella: desde aquellas películas que narran los sueños de un personaje por ser una estrella del mundo artístico, el melodrama romántico y el difícil equilibrio entre vida personal y carrera profesional. Se trata solo de tres de algunos de los géneros o tipos de películas que inspiran el guion de La La Land que, como pastiche postmoderno, busca un mensaje original y actual partiendo de la cinefilia, el homenaje y la nostalgia.

\begin{abstract}
Within its generic classification, La La Land was labelled as a romantic musical. Although there is no doubt that it is a musical, this paper aims to reflect on its consideration as romantic work, since anti-romantic features can also be found within the postmodern context in which the film was created. For this purpose, an introduction to the concepts of Romanticism and anti-romanticism will be made and then the study of the film will be presented from three different points of view which seem to coexist in it: from those films which deal with the dreams of a character for being a star of the art world, the romantic melodrama and the difficult balance between personal life and professional career. They are only three of the genres or types of films which inspire the script of La La Land that, as a postmodern pastiche, looks for an original and contemporary message based on cinephilia, homage and nostalgia.
\end{abstract}

Palabras clave:

La La Land; Romanticismo; antirromanticismo; postmodernismo; pastiche

Keywords:

La La Land; Romanticism; anti-romanticism; postmodernism; pastiche 


\section{Introducción}

La La Land (2016) de Damien Chazelle pertenece a ese grupo de películas que consiguió unir a público y crítica en sus halagos, lo que se tradujo posteriormente a un reconocimiento casi generalizado en los principales galardones cinematográficos mundiales ya que consiguió seis Premios Oscar, siete Globos de Oro, cinco Premios BAFTA y ocho Premios de la Crítica Cinematográfica, entre otros muchos. La fama alcanzada por la película suscitó también numerosos comentarios y críticas que llamaron la atención sobre diferentes elementos tratados en la cinta tan diversos como el imaginario de la ciudad de Los Ángeles, el atrevimiento por hacer un musical en los tiempos actuales, la cinefilia (y, a partir de ahí, la nostalgia y el homenaje), la visión que se da sobre el mundo del jazz o la escasa presencia de personajes que no sean de raza blanca. En cambio, la mayoría de los aspectos estudiados aparecieron en la prensa y en revistas de cine y, en menor medida, en publicaciones de carácter científico. Dentro de este ámbito, el presente artículo pretende hacer una aportación que, además, trate una vertiente a la que no se le ha prestado la debida atención y que también puede ser de relevancia dentro de las ideas creativas expuestas en la película y del contexto sociocultural postmoderno en el que se fraguaron.

De tal forma que, de la misma manera que hubo una recepción muy positiva cuando apareció La La Land, cierta unanimidad también se ha seguido en la clasificación genérica al etiquetarse la película, entre otras formas, como musical romántico. Así, si bien es cierto que se trata de un musical, el presente artículo pretende reflexionar sobre hasta qué punto se puede considerar como una película romántica ya que, aunque existen rasgos que apoyan esta idea, también están presentes algunas características antirrománticas que se encuadran en las ideas creativas que se siguen.

Para ello, se hará en primer lugar una introducción básica a los conceptos de Romanticismo y antirromanticismo. A continuación, se comprobará cómo algunos de estos rasgos románticos y antirrománticos que están presentes en La La Land tienen cabida en distintos tipos de obras cinematográficas que 
parecen convivir en la película en tanto que, como producto de su época, se puede considerar como pastiche postmoderno. De hecho, se ha llegado a comentar que se podría escribir una tesis con todas las películas que hay detrás de ella (Rodríguez, 2016). En ese sentido, el presente estudio se centrará en tres clases de películas: aquellas películas en cuyo argumento el protagonista quiere alcanzar el sueño de ser artista, el melodrama romántico y las películas que muestran las dificultades por alcanzar un equilibrio entre la vida personal y la profesional.

Uno de los hilos argumentales principales de La La Land es el deseo de la pareja protagonista por ser artistas y, en ese relato, irán apareciendo algunas reflexiones sobre las implicaciones que supone tener una vida de artista que tienen conexiones con el Romanticismo. Una aproximación interesante al respecto se puede encontrar en las propias palabras de una escritora romántica como George Sand. En sus memorias comentaba:

iSer una artista! Sí, quería serlo, no solo para escapar de la prisión material donde la propiedad, grande o pequeña, nos encarcela en un círculo de pequeñas preocupaciones odiosas, sino para aislarme del control de la opinión... vivir lejos de los prejuicios del mundo. (1928, pp. 159-160)

Una afirmación que ya refleja ese papel diferenciador entre el artista y quien no lo es, puesto que son dos formas de vivir distintas hasta el extremo de que el artista puede llegar al aislamiento. Además, en el Romanticismo:

Querer ser artista o denominarse con tal palabra era una manera de distinguirse de lo establecido y de los artesanos (incluso de los escribientes, en el caso de los escritores, con los que a veces eran confundidos, como recordaba Larra), era una forma de contestación social, aunque fuera moderada. (Álvarez, 2002, p. 28)

Así, en uno de los aspectos que Rilke comparte con el Romanticismo, varios de sus escritos "indican claramente que ser un artista exige una cierta forma de estar en el mundo" (Fisher, 2015, p. 100), un rasgo que viene determinado, en parte, por las nuevas ideas artísticas de imaginación, originalidad, autonomía artística y libertad de creación (Bravo, 2007, p. 139). En lo que se refiere a este último aspecto "[l]a libertad del artista romántico 
no es sólo un supuesto metafísico sino también la condición empírica de la vida del nuevo artista" (Tollinchi, 1989, p. 238), ya que el individualismo del artista supone que se ha emancipado de sus antiguos patronos y mecenas y, por tanto, la función de su obra de arte es otra. Una de estas implicaciones supone también aportar originalidad, algo que refleja el ya clásico estudio sobre el Romanticismo The Mirror and the Lamp (1953) de M. H. Abrams cuyo título muestra la propuesta diferenciadora de los románticos que, lejos de querer en sus obras de arte una representación mimética de la realidad, buscaron iluminar el mundo arrojando sobre él su propia luz interior como creadores. Desde un punto de vista psicológico, las creaciones artísticas son una ejemplificación de las cualidades del artista, definidas por el genio y la imaginación, y que en muchas ocasiones son producidas en soledad (Vallins, 2000, p. 23). Schopenhauer "acentuó el rasgo del aislamiento estético, y este concepto proporciona el acceso más rápido a su idea sobre la belleza, el arte y la experiencia estética” (Wellbery, 2012, p. 21). En literatura también es el caso tanto de Wordsworth como de Coleridge, dos figuras señeras del Romanticismo inglés, quienes hicieron referencia a la figura del ermitaño en destacadas obras suyas como The Rime of the Ancient Mariner y Lyrical Ballads, no en vano la figura del genio incomprendido es uno de los mitos sobre el artista romántico (Wu, 2015, p. 41). De manera que se podía dar el caso de que los románticos "concebían la locura como una de las tentaciones o excesos a que se sentía llamado el artista en su rebeldía” (Atienza, 2009, p. 57), aunque se trata de un punto extremo.

En lo que se refiere al melodrama hay que resaltar que, ya en la década de los 70, Jacques Goimard hizo un estudio de 52 películas del periodo clásico de Hollywood (entre los años 1931 y 1949) y trazaba un diagrama, llamado $L a$ rosa de los géneros, en el que situaba al melodrama en un lugar central en relación a los otros géneros (Goimard, 1976, pp. 34ss), una vinculación que alcanzaría incluso al musical (Marzal, 1998, p. 279). Estas ideas siguen estando en vigor y se defiende la transversalidad de los aspectos melodramáticos para cualquier género cinematográfico (Gómez, 2018, p. 41). Dicho aspecto transversal es el que hace que en La La Land, dentro de la estética de un musical, confluya el romántico sueño de ser artista con otro 
aspecto más prosaico y actual como es la problemática entre la vida profesional y la vida personal.

En relación a este último rasgo se ha afirmado que:

Durante la segunda mitad del siglo pasado han ocurrido en los países desarrollados grandes cambios, sociales, demográficos, económicos y culturales. [...] Al mismo tiempo, se han manifestado de manera creciente conflictos entre la vida familiar y la profesional. (Ponce, 2007, p. 182)

La incorporación de la mujer al mercado laboral es uno de los factores que han contribuido a ello ya que ha replanteado el cuidado de las personas dependientes, lo que ha hecho que se reflexione en este contexto sobre la influencia entre el mundo laboral y el personal, el equilibrio a alcanzar entre ambos y que se utilice cada vez más el término “conciliación”. Esta realidad se ha reflejado en el mundo de la imagen sobre todo por medio de series televisivas, como ocurre, en cierta medida, en Anatomía de Grey; en cortometrajes, como Globos de agua (2007) de Fernando Canet; y en el cine desde diferentes puntos de vista y con distintos objetivos y resultados, como se verá más tarde en los ejemplos que se darán, entre los que La La Land cobra un papel singular.

\section{Romanticismo y antirromanticismo}

Cuando se menciona el término "romanticismo" un referente claro es el de un movimiento histórico en el arte y las ideas que tuvo lugar en Europa y América entre finales del siglo XVIII y principios del XIX, pero también es un término que se utiliza para referirse a "una característica general y permanente del pensamiento, el arte y la personalidad que se encuentra en todos los periodos y culturas" (Peckham, 2007, p. 1). De manera que, como indica Butler: "El Romanticismo está inconcluso porque no es solo un movimiento intelectual sino un conjunto de respuestas a ciertas condiciones que la sociedad occidental ha experimentado y continúa experimentando desde mediados del siglo XVIII” (1982, p. 184). De ahí que, aunque el movimiento cultural ya concluyese, no es complejo rastrear parte de su espíritu en creaciones artísticas posteriores y también en alguna anterior, no 
en vano una obra como Romeo and Juliet de Willliam Shakespeare se ha llegado a considerar como la quintaesencia del amor romántico (Santibáñez, 2003, p. 169). En ese sentido, y ya entrando en el campo cinematográfico, no es de extrañar que una de las más conocidas películas románticas haya sido el célebre musical West Side Story (1961). Además, se pueden recordar otros ejemplos de películas que siguen este tipo de romanticismo, pero diferentes entre sí como The Shop Around the Corner (1940), Love Story (1970), Ghost (1990), The Notebook (2004).

Por otra parte, hay que tener en cuenta que la sátira y la parodia del Romanticismo fue un fenómeno paneuropeo y corrió en paralelo al desarrollo de la escuela romántica (Comellas, 1996, p. 357). Además, hubo una reacción antirromántica posterior, que apeló a una estética más realista y que estuvo presente dentro del Modernismo en distintos campos como la filosofía, la literatura y la crítica literaria (Al-Dabbagh, 2014, p. 56). Este antirromanticismo también se muestra como una corriente opuesta al romanticismo cuando se lo considera como esa tendencia abstracta o sensibilidad. En lo que se refiere al cine, desde sus comienzos se pueden encontrar títulos de películas que se han calificado como romance o románticas como es el caso de Broken Blossoms (1919), Sunrise (1927) o Lucky Star (1929). Y, como contrapunto a este tipo de sensibilidad que ha continuado a lo largo de la historia del cine, también han aparecido títulos que se pueden considerar como reacciones antirrománticas, como es el caso de Looking for Mr. Goodbar (1977), Sleeping with the Enemy (1991), Happiness (1998).

La complejidad que supone definir el movimiento artístico romántico y el hecho de que romanticismo y antirromanticismo son dos corrientes opuestas que conviven son algunos de los motivos que han hecho pensar de qué manera se puede concretar el concepto de amor romántico, presente no solo en el cine sino también en algunas publicaciones. En este sentido Lantz, Keyes y Schultz lo definieron en cinco aspectos: la idealización de la persona amada, solo se puede amar a una persona, amor a primera vista, el amor lo puede todo y la glorificación de las emociones (1975, p. 28), dentro de un 
estudio que hicieron sobre la familia en Estados Unidos en la época preindustrial y considerando, entre otros aspectos, el contenido de importantes revistas de la época. Es el modelo que siguieron Sprecher y Metts (1989) para su escala de creencias románticas (RBS en inglés, por Romantic Beliefs Scale). Más allá de los matices que se han hecho dentro del campo sociológico, "la RBS es una de las escalas más utilizadas para medir las creencias románticas” (Adamczyk y Metts, 2014, p. 218), por lo que será uno de los aspectos que se comentarán en el estudio de La La Land. Y casi como una consecuencia de estos cinco factores sobreviene hacer una consideración sobre el final. Hablando sobre el alto porcentaje de películas de Hollywood que tienen un final feliz se ha indicado que "[e]l final feliz, además, puede no solo implicar una restauración del orden, sino la unión de la pareja romántica como una parte intrínseca de esa restauración. El final feliz inspirado por el orden está unido con frecuencia al final feliz de la historia de amor" (Strinati, 2000, p. 34). No en vano Hollywood ha modificado en numerosas ocasiones los finales de los guiones o las obras literarias que se han adaptado al cine para presentar finales más amables.

En La La Land, como se irá viendo en el posterior análisis sobre tres tipos posibles de películas que se pueden distinguir y el tratamiento que se le da a la RBS, existen elementos tanto románticos como antirrománticos. Además, La La Land es un producto de la postmodernidad y en dicho ámbito es habitual que se encuentre un carácter antirromántico definido. Así, se ha indicado que:

El antirromanticismo es [...] incluso más destacado en el así llamado arte y teoría postmodernista, donde los pensadores y teóricos [...] han desterrado cada vestigio del romanticismo, rechazando cualquier aspiración hacia los ideales de autenticidad o unidad del yo, la espontaneidad apasionada o el contacto directo con el mundo. En su lugar, han llegado a considerar formas de alienación o desapego como el indispensable logro estético del significante. Incluido entre los objetivos de la crítica postmoderna está, de hecho, la misma noción de la propia creatividad, que se considera como un énfasis excesivo de las defectuosas e incluso sentimentales nociones de espontaneidad, originalidad y genio individual (Runko y Pritzker 1999, p. 504). 
En lo que se refiere a esa originalidad o autenticidad, hay que destacar que uno de los rasgos o prácticas más significativos del postmodernismo es el pastiche (Jameson, 1985, p. 113). En el mundo del cine en concreto fue Blade Runner (1982) la primera película que provocó una discusión sobre pastiche y postmodernismo (Hoesterey, 2001, p. 47). La necesidad de experimentar con un lenguaje propio y personal hace que el nuevo discurso creado se llene de ecos de otros lenguajes conocidos, de manera que "[m]ás que otro medio, el cine ha utilizado la repetición y la parodia para la mejora del lenguaje” (Oliva, 1996, p. 76), un nuevo lenguaje en el que, como pastiche, también tiene cabida la nostalgia (Austin, 2013, p. 136). En efecto, la época en la que proliferaban los musicales correspondió con los años de la Gran Depresión, donde el público buscaba evadirse, por lo que Chazelle sabía que si quería que su musical fuera aceptado tendría que ser por medio de la parodia, el homenaje y la nostalgia (Golding, 2017). No en vano, la película comienza con unas imágenes en blanco y negro que hacen saber que está rodada en cinemascope. Será la puerta de entrada al número musical con el que comienza una cinta que contiene rasgos de diferentes tipos de películas.

\section{El sueño de ser artista}

Son numerosas las películas que han narrado las vicisitudes que tiene que atravesar un personaje que, desde el anonimato, busca el éxito profesional y el reconocimiento del público en su carrera artística, ya que anhelan ser cantantes, actores, músicos, bailarines y, en menor medida, humoristas o escritores. Así, en esa búsqueda por triunfar en el mundo del espectáculo el deseo máximo es hacerlo en Hollywood o en Broadway. A estos personajes se les ha llegado a denominar como dreamers o wannabes. Se trata de un tipo de película que suele conectar muy bien con los espectadores, quienes pueden traducir el logro de esos sueños con la consecución de los suyos $\operatorname{propios}^{1}$.

\footnotetext{
${ }^{1}$ Dentro de este tipo de películas algunas son musicales y otras no lo son. No son musicales películas como: Movie Crazy (1932), Stage Door (1937), A Star is Born (1937), All About Eve (1950), The Bad and the Beautiful (1952), Punchline (1988), Man on the Moon (1999), Billy Elliot (2000), Black Swan (2010), The Artist (2011), Frances Ha (2012). Ejemplos de
} 
En los ejemplos que se pueden encontrar dentro de estas películas cabe destacar que en The Red Shoes también hay una relación amorosa entre una bailarina y un compositor, y en Moulin Rouge se narra la relación entre la bailarina estrella del famoso cabaret parisino, que aspira a ser actriz, y un joven que desea ser escritor, lo que son puntos de conexión con La La Land, donde la pareja protagonista la forman una aspirante a actriz y un músico que busca abrir su propio negocio.

Esta búsqueda por conseguir el sueño artístico ya de por sí tiene mucho de romántica, y así se reconoce en la serie documental La historia del cine: Una odisea (The Story of Film, Mark Cousins, 2001), cuando se describe: "la fruslería de Hollywood: brillante y romántica, con su promesa de escapismo y perfección”. Puesto que es muy romántico también buscar ese idealismo. Por eso, los protagonistas de La La Land se mueven entre la autenticidad y la copia, entre el punto en el que se encuentran y dónde está su objetivo. Es algo que aparece reflejado en la canción "Another Day of Sun”, con la que arranca la película y que comienza con una joven cantando:

Pienso en aquel día

Lo dejé en la estación de Greyhound

$\mathrm{Al}$ oeste de Santa Fe

Teníamos 17 años, pero él era dulce y todo era verdadero

Pero hice lo que tenía que hacer

Porque lo sabía.

En las noches de domingo de verano

Nos hundíamos en los asientos

Cuando las luces se apagaban

Y un mundo en tecnicolor hecho de música y máquina

Me llamaba a estar en la pantalla².

musicales son: The Red Shoes (1948), An American in Paris (1951), Singin' in the Rain (1952), Funny Face (1957), Wild Guitar (1962), Les demoiselles de Rocheford (1967), All That Jazz (1979), Fame (1980), Victor Victoria (1982), Flashdance (1983), A Chorus Line (1985), The Thing Called Love (1993), Shine (1996), Center Stage (2000), Moulin Rouge (2001), Whiplash (2014).

${ }^{2}$ La letra original al completo de la canción e información añadida se encuentra en: https://genius.com/La-la-land-cast-another-day-of-sun-lyrics (recuperada el 10 de julio de 2018). 
Pero para conseguir el objetivo de ese sueño hay que recorrer un camino que no es sencillo y en el que hay buenos y malos momentos. Por este motivo resulta significativo este comienzo, que muestra uno de los habituales atascos de tráfico en la ciudad de Los Ángeles. Pese a ello, hace un día radiante y los conductores deciden afrontar con optimismo una situación que no está bajo su control poder cambiar. Además, el coche se puede entender aquí como una metáfora del viaje, del camino que hay que recorrer y que supone un cambio en la vida (Chevalier y Gheerbrant, 2007, p. 153), y volverá a aparecer más tarde en otras escenas en la relación entre los protagonistas. Y si quieren conseguir ese objetivo una de las reflexiones de La La Land gira en torno a mantener la autenticidad, algo que defienden tanto Mia como Seb.

De tal manera que, por un lado, se encuentra el protagonista masculino, Seb, que ha sido despedido del club en el que tocaba el piano porque no aceptó el repertorio según el cual tenía que tocar música de fondo a la que nadie presta atención. Cuando es readmitido vuelve a tocar jazz, su verdadero deseo, y el propietario del local vuelve a despedirlo. Seb defiende la autenticidad de un jazz puro, por eso lamenta que un antiguo club de jazz se haya convertido ahora en un local de samba y tapas; por eso es un fetichista con aquello que tiene que ver con la música que él ama y no quiere que su hermana toque el taburete que, al final, acabará ocupando un lugar de preferencia en su club. Se trata de una postura muy romántica, como él mismo reconoce en la conversación que tiene con su hermana en la que comentan la estafa que sufrió con sus últimos socios, y él trata de matizarlo utilizando eufemismos:

- LAURA (L): No suena tan romántico. Todo el mundo sabía que ese tipo no era legal menos tú.

- SEBASTIAN (S): ¿Por qué dices romántico como si fuera algo vulgar?

- L: Las facturas pendientes no son románticas.

Pero Seb se siente cómodo viviendo en esa vida de ermitaño, como la califica Laura en esta misma escena, y sin relacionarse con nadie que no entiende su pasión. Cuando, más tarde, Mia encuentra a Seb en la fiesta que tiene lugar a comienzos de la primavera, Seb forma parte de un grupo que toca música electrónica de los años 80, un estilo que, con cierta arrogancia, asegura que 
no está a su altura puesto que se considera un músico serio $\mathrm{y}$, en la conversación que tiene después con Mia, simula que es él quien se está dejando dar órdenes. Finalmente, cuando acepta la oferta como teclista en el grupo de su amigo Keith, interpretado por el artista John Legend, el tipo de jazz que tocan no es el jazz puro que él quiere hacer, más allá de que esté teniendo éxito de público. Pero todo ello lo hace porque es una forma de ganarse la vida con la música y, sobre todo con este último trabajo, de obtener el dinero suficiente que necesita para conseguir su sueño de abrir su propio local.

Por su parte, Mia, que desea ser actriz, procura evitar durante toda la fiesta antes indicada al guionista que allí le presentan, quien le cuenta sus proyectos, entre los que se encuentran nuevas versiones de obras de otros autores, algo tan poco auténtico que hace que a Mia no le parezca interesante la conversación. Aparte de este detalle, muestra su pasión por el auténtico cine en la cena que está compartiendo con Greg (su novio entonces), el hermano de Greg y la prometida de este. El hermano de Greg presume del equipo de sonido que ha comprado, que le permite disfrutar de una experiencia como si estuviese en el propio cine, con lo que evitaría las incomodidades que supone mezclarse con otras personas en una sala. Pero Mia sabe que la verdadera experiencia del cine hay que vivirla en una sala. Además, tiene presente durante toda la velada que Seb debe estar esperándola así que, cuando la canción que tocaba Seb al piano el día de su (des)encuentro en el club sale desde uno de los altavoces del restaurante, que se encuentra junto al significativo letrero de "Exit", abandona la mesa precipitadamente para ir a encontrarse con él, para disfrutar de la magia del cine junto a una persona con la que comparte sueños artísticos. Cuando ya han comenzado su relación de pareja, Mia le confiesa a Seb su preocupación porque considera que la pieza teatral que está escribiendo puede resultar muy nostálgica, un aspecto que ya se mencionó con anterioridad, pero él la anima a que continúe escribiendo el tipo de obra que ella quiere escribir. Esta respuesta y el hecho de que la obra sea un monólogo suponen una defensa del individualismo muy romántica. Tras el aparente fracaso de la obra, Mia decide abandonar, pero Seb la convence para que haga un último intento en 
la prueba de selección a la que ha sido citada y de la que ella no tenía noticia. Es el momento en el que Mia decide jugarse todas sus posibilidades y canta "Audition (The Fools Who Dream)", donde habla sobre las historias que le contaba su tía y de donde se pueden destacar los siguientes versos:

Ella me dijo:

"Un poco de locura es la clave

Para permitirnos ver nuevos colores

¿Quién sabe dónde acabaremos?

Y por eso nos necesitan”.

Que vengan los rebeldes

Las ondas de los guijarros

Los pintores, poetas y obras.

Y brindo por los tontos que sueñan

Por locos que parezcan

Brindo por los corazones que se rompen

Y la confusión que creamos.

Lo remonto todo a ese momento

A ella, y la nieve, y el Sena

Y ella sonriendo

Dijo que lo haría otra vez 3 .

Porque todos aquellos que albergan el deseo de ser artistas tienen un punto de diferenciación que les hace parecer locos a los ojos de muchas otras personas; porque la pasión que se siente por aquello que se ama es tal que no resulta sencillo renunciar $\mathrm{y}$, en numerosas ocasiones, provoca la incomprensión de los demás.

Ese romanticismo incomprendido es el que está presente en la posición que Seb mantiene sobre el tipo de jazz que defiende, que es una música que pertenece a otra época. $\mathrm{Su}$ amigo Keith trata de que reflexione al respecto diciéndole:

3 Ídem. 
Dices que quieres salvar el jazz. ¿Cómo vas a salvarlo si nadie lo escucha? El jazz muere por culpa de gente como tú. Tú tocas para gente de noventa años en el Light House. ¿Dónde están los niños y la gente joven? iEstás tan obsesionado con Kenny Clarke y Thelonious Monk! Ellos eran revolucionarios. ¿Cómo vas a ser revolucionario siendo tan conservador?

Esta diferencia entre los tradicionalistas y los partidarios de la evolución es uno debates en la historia del jazz, un fenómeno musical de tal complejidad que sus mismas raíces mestizas hacen que sea arriesgado situar dónde puede radicar su grado de pureza. No obstante, Seb se mantiene en su postura, que es muy romántica en cuanto a su idealismo, y cuya reflexión se puede extender hacia el mundo del cine:

Igual que el jazz fusión se erige en la película como un temible horizonte estético, así La La Land se presenta para aplacar los miedos de que el cine pueda estar en el proceso de unirse con algo más allá o fuera de él, un proceso que Chazelle denomina ‘bastardización' (Stevenson, 2017).

Chazelle, como cinéfilo, busca la pureza del cine pero, aunque sabe que tiene que avanzar para no morir, no desea mezclar el cine con elementos que considera extraños. Así, se afirma también:

Chazelle presenta una versión de Los Ángeles en la que el cine nunca fue suplantado o suplementado por los medios más modernos, lo que también implica una versión de Los Ángeles en la que las múltiples voces y perspectivas abiertas por estos nuevos medios son nostálgica y categóricamente silenciadas (Stevenson, 2017).

Por lo que se podría entender que Chazelle puede tener sus reservas sobre la digitalización cinematográfica. En relación a todo ello, es significativo también el comienzo de la estación de verano en La La Land. Una vez que ya han empezado su relación, Seb va a buscar en su coche a Mia a su casa. Tras ello, toma una calle que es dirección prohibida como imagen del camino a contracorriente que tienen que recorrer. Tanto la defensa de la libertad creadora, más allá de ciertas consecuencias, como el individualismo son rasgos muy románticos y, metadiscursivamente, se pueden entender también como una justificación de esta película en sí. 


\section{El melodrama romántico}

En lo que se refiere al argumento del melodrama romántico se trata de películas que, de manera habitual, narran los hechos que tienen lugar a partir de que un hombre y una mujer, normalmente jóvenes, se conocen y entablan una relación amorosa que suele seguir el esquema de: encuentro, atracción, unión, crisis y, finalmente, reconciliación o separación amistosa. Pueden presentar el registro cómico y el dramático. Lo habitual es que en las comedias exista el final feliz por medio de la reconciliación y los dramas concluyan con la desunión, derivada, en la mayoría de los casos, por justificaciones sentimentales. Además, algunas de estas películas son también musicales como es el caso de los clásicos Brigaddoon, Gigi, Les Parapluies de Cherbourg o de One from the Heart. La película de Francis Ford Coppola presenta la curiosidad de que, cuando el matrimonio decide separarse, cada uno de ellos encuentra la posibilidad de una nueva vida sentimental con personas del mundo de la farándula (un camarero pianista y una artista de circo). Sin embargo, hay que resaltar que en Absolute Beginners el motivo de la ruptura surge en el momento en el que la protagonista tiene la primera ocasión de desarrollarse profesionalmente (como modelo, en este caso), e incluso acepta casarse con su jefe pese a haber una destacada diferencia de edad entre ellos. Y la reacción del personaje masculino, que sobrevive como fotógrafo, será también la de buscar el éxito profesional en su campo. Finalmente, cuando descubren las corruptelas inmobiliarias que aparecen enmarcadas en los disturbios raciales que tuvieron lugar en el londinense barrio de Notting Hill en el verano de 1958, ambos se reconcilian.

Sin embargo, en La La Land se encuentran distintos cambios en relación a todo lo recién indicado. Los protagonistas, como ya se señaló, quieren ser

\footnotetext{
4 Ejemplos de comedias son: Brigadoon (1954), Gigi (1958), One Fine Day (1996), PunchDrunk Love (2002), (50o) Days of Summer (2009), Ruby Sparks (2012). Mientras que la carga dramática es mayor en películas como: Brief Encounter (1945), Letter from an Unknown Woman (1948), Marty (1955), An Affair to Remember (1957), Les Parapluies de Cherbourg (1964), One from the Heart (1982), Absolute Beginners (1986), The Bridges of Madison County (1995).
} 
artistas y, desde la primera escena al espectador le queda claro que está ante un musical. En lo que se refiere al esquema del melodrama romántico hay modificaciones que buscan un punto de originalidad. El amor a primera vista es una convención literaria presente en el mundo occidental desde la antigüedad grecolatina y que encuentra algunos ejemplos cinematográficos en Forrest Gump (1994), Titanic (1997), Twilight (2008), Wall-e (2008). Sin embargo, los primeros encuentros entre Mia y Seb poca relación tienen con la atracción y el romanticismo: el primero en el atasco de tráfico con el que comienza la película y el segundo cuando Seb la ignora en el club tras ser despedido. Sin embargo, Mia ve el momento de devolver el golpe en la fiesta que tiene lugar en primavera, cuando ve que Seb forma parte de un grupo de música electrónica y les pide que toquen "I Ran”. Gracias a ello, tendrá lugar el primer diálogo entre ellos en el que, aunque él se disculpa por su actitud en el club, ambos se lanzan varias indirectas sobre sus respectivos trabajos. Pese a ello, al final de la fiesta, deciden caminar juntos con la justificación de que van a buscar sus respectivos coches. La escena que se presenta entonces es la de dos jóvenes que acaban de entablar su primera conversación en una fiesta y han llegado paseando de noche a Cathy's Corner, desde donde se divisa la ciudad de Los Ángeles con sus luces. En este ambiente romántico ambos bailan en un número que se puede vincular fácilmente con Singin' in the Rain. Se trata de solo un ejemplo de las numerosas vinculaciones de La La Land con otros musicales y que demuestran el conocimiento que Chazelle tiene sobre ellos (Dargis, 2016). A continuación, también cantan la canción “A Lovely Night”, cuya letra es irónica en relación al título ya que ambos procuran minimizar ese ambiente romántico tratando de demostrar que no les afecta, ya que dicen estar de acuerdo en que no sienten nada el uno por el otro, por lo que esa noche romántica es una pérdida de tiempo porque no tiene sentido. Pero esta letra antirromántica no se corresponde con el principio de atracción que están sintiendo, ya que en la escena siguiente Seb va a buscar a Mia a la cafetería con la idea de seguir conociéndose, y ella acepta dar otro paseo con él en el que le va a mostrar distintos decorados de los Warner Bros Studios. Es el momento en el que ambos comparten sus sueños y empiezan a animarse mutuamente. Entonces Mia le dice a Seb que 
tiene que prepararse un papel que se parece a Rebel Without a Cause (1955) pero que no ha visto la película. Seb le propone ir juntos a verla con la justificación de que van a hacer eso "como investigación”, en un intento por parte de ambos de ocultar que se trata de una cita amorosa. En dicha cita, se cogen de las manos en el cine y en el momento en el que están a punto de besarse, la cinta se corta (en otro detalle que recuerda las salas de cine de hace décadas), por lo que, a modo de continuación de la película que están viendo, deciden ser ellos los que vayan al Observatorio Griffith y es allí donde tiene lugar un número de baile en el que, para expresar la felicidad que sienten por haberse conocido, ambos flotan en el aire, un detalle que puede recordar a Everyone Says I Love You (1996) y la escena acaba, al fin, con el primer beso entre ambos, a lo que sigue la técnica del iris shot, que es un guiño al estilo de las películas románticas mudas (Vineberg, 2005, p. 81). Llegados a este punto, y siguiendo el esquema que se avanzó antes, tendrán que vivir una crisis y superarla. La crisis llega en el momento en el que Seb consigue tener ingresos fijos cuando toca en el grupo de su amigo Keith. El éxito que alcanzan hace que, entre grabaciones, gira y publicidad, no le quede mucho tiempo que compartir con Mia. Pese a que ambos discuten sobre el estado de su relación en esos momentos, Mia toma la decisión de marcharse a casa de sus padres cuando, después del fracaso de su obra teatral, siente que ya no tiene sentido seguir intentando que su sueño artístico se cumpla. Se trata de un avance de lo que ocurrirá algo más tarde. Cuando se plantea el verdadero motivo de la ruptura se debe a una cuestión laboral. Ambos están de acuerdo en que cada uno de ellos debe seguir su camino: ella en París y él abriendo su club en Los Ángeles. En la escena en la que hablan sobre esto ambos se dicen que se querrán siempre. En los musicales clásicos “Astaire no le decía a Rogers que la amaba porque no necesitaba decírselo. Ella lo sabía y nosotros también- por la forma en la que bailaban juntos” (Brubach, 2017). Pero en La La Land tanto los bailes como las otras experiencias que han compartido Mia y Seb han formado parte de una etapa de sus vidas que ahora deben cerrar. Justo porque saben esto y porque no se han idealizado como amantes se dicen que se amarán, pero en ningún momento dicen que estarán juntos siempre. Son conscientes de que tienen que sacrificar su 
relación si quieren conseguir sus objetivos y no dudan en hacerlo. Esta idea de amor y sacrificio puede recordar a Casablanca (1942), una película a la que se alude en La La Land: Mia tiene un poster de Ingrid Bergman en su habitación, y cuando Mia le va enseñando los decorados cinematográficos a Seb le señala una ventana desde la cual tanto Ingrid Bergman como Humphrey Bogart miraban en dicha película. Pero el sacrificio de los protagonistas de Casablanca es muy diferente del que hacen Mia y Seb, que poca relación tiene con el romanticismo.

\section{Vida personal y vida profesional}

Ante la creciente preocupación por la conciliación laboral en la sociedad actual, el cine ha respondido, desde hace unos años, con diferentes películas que han reflexionando sobre la dualidad entre la vida personal-sentimental y la vida profesional, y la complejidad por compaginarlas, algo que se ha mostrado tanto en el registro cómico como en el dramático.

Así, en The Devil Wears Prada (2006) la protagonista acepta el trato degradante de la directora de una influyente revista de moda solo porque ese trabajo puede suponer que se le abran otras puertas profesionales en el futuro, y da ese paso aunque suponga cortar la relación con su novio pero, finalmente, acaba reconciliándose con él cuando rechaza todo el mundo de fama, estilismo y sofisticación con el que se ha familiarizado. Aunque la situación habitual es que sean personas ya asentadas laboralmente y muy entregadas a su trabajo las que se vean, por un motivo u otro, en la coyuntura de replantearse sus vidas. De tal manera que el protagonista de Up in the Air (2009), frío y desarraigado, sufre un gran golpe emocional cuando descubre que no puede empezar una relación sentimental seria con una mujer por la que se siente atraído. Otras veces, es la aparición inesperada de una nueva persona la que cambia sus vidas. En Baby Boom (1987) una ejecutiva ve alterada su rutina por un bebé que recibe como herencia de un primo suyo, y en Somewhere (2010) un exitoso actor que lleva una vida de lujo y excesos cuando se presenta su hija de once años, fruto de su fracasado matrimonio. En el caso de Family Man (2000) el cambio es impuesto dentro del ambiente 
mágico navideño, muy propicio para historias de redención, y un bróker de Wall Street es obligado a comprobar cómo sería su vida si se hubiese casado con su novia en vez de seguir con su carrera profesional, como hizo en su día cuando tuvo que elegir. Como contraste a estos ejemplos, habría que citar el caso de An Education (2009). Aquí la protagonista es una adolescente que tiene que sopesar las ventajas y los inconvenientes entre la vida de los estudios (que la puede conducir a la universidad de Oxford y, a partir de ahí, a un buen futuro laboral) y la "universidad de la vida", tal como se la muestra un grupo de adultos. Se presentan como dos opciones incompatibles y los personajes de cada uno de los mundos son destacadamente maniqueos, lo que lleva al guion a señalar con claridad cuál es su opción preferida.

En efecto, la mayoría de las películas recién citadas tienen un planteamiento muy romántico puesto que presentan los beneficios de la vida hogareña, sentimental y familiar como una opción preferible frente al éxito, el dinero y el reconocimiento profesional. Sin embargo, es significativo que en el caso de An Education, más allá de la factura y del planteamiento de la película, se tenga una visión distinta, lejos del sentimentalismo y mucho más apegada al pragmatismo. Esta línea es la que sigue también en cierta manera $L a L a$ Land. Tras la ruptura acordada, la acción se sitúa cinco años más tarde. Mia es ya una actriz reconocida que acude, ahora como cliente, a la cafetería en la que ella trabajaba como camarera. Pero no hay aquí ningún deseo en Mia por demostrar su actual posición, sino que se trata de una reflexión en torno al ciclo de la vida. Vuelve a ser invierno, como al principio de la narración. De tal forma que la película se estructura en base a las estaciones que señalan de forma metafórica el paso del tiempo y el cambio. Pero lo que cambian son los personajes, no las situaciones, que presentan la misma estabilidad que el clima de Los Ángeles. Ahora Mia disfruta de su anhelada posición y en apariencia está felizmente casada con un hombre con el que tiene una hija en común, un hecho que va contra la idea de que solo se puede encontrar el amor con una única persona. El encuentro casual del club de Seb hace que el guion fantasee con lo que pudo haber ocurrido si hubiesen decidido seguir juntos. En dicha suposición, Seb rechazaría la oferta de Keith; acudiría al estreno de la obra de Mia (que sería un éxito) y la acompañaría después a 
París, donde tocaría en Le Caveau de la Huchette, un club de jazz en el Barrio Latino de la capital francesa; tendrían un hijo y luego regresarían a Los Ángeles. Por lo que si Mia hubiese continuado con un artista como Seb su vida habría sido algo más alegre y colorida en el plano personal; y Seb, por su parte, no estaría solo pero no tendría su propio club, en un ejemplo de las dificultades por encontrar un equilibrio entre ambas facetas. Para continuar juntos uno de los dos debería sacrificar su sueño y ninguno de los dos está dispuesto a renunciar a su objetivo artístico, porque el amor no siempre lo puede todo. En el caso de Seb, el único recuerdo familiar que tiene en su casa es la foto de su hermana, que se ha casado y también tiene un hijo y que, desde el comienzo de la película con su propuesta para que salga del piso y conozca a otras personas, representa una estabilidad familiar que Seb no desea si eso supone trastocar sus planes profesionales. Y todo ello lleva a un final en el que Seb y Mia se observan en la distancia y él le hace un gesto de aprobación. La carrera hasta alcanzar el sueño profesional artístico es larga y dura como para renunciar a ella por cuestiones sentimentales, por tanto, siendo más racional que pasional, el amor pasaría a un segundo plano ya que se puede encontrar con más de una persona y, en el caso de no surgir, tampoco sería relevante. Un mensaje muy alejado de los habituales finales felices de los cuentos de hadas o de muchas películas románticas en los que los protagonistas acaban juntos y felices. Se trata de un final no tan edulcorado y más apegado a la realidad y al contexto sociocultural postmoderno. Un final que muestra una posible respuesta ante un asunto de actualidad y que, en líneas generales, resulta altamente antirromántico.

\section{Conclusión}

La La Land es un musical en el que el argumento participa de una mezcla de distintos tipos de películas: dos jóvenes que residen en Los Ángeles y quieren cumplir sus respectivos sueños artísticos se conocen y empiezan una relación amorosa sobre la que tendrán que tomar una decisión en el momento en el que el ansiado éxito les llega, y eso supone que se tengan que separar. Dentro de esta mezcla de distintos tipos de película se pueden seguir rasgos 
románticos y antirrománticos. Los protagonistas son románticos en la búsqueda de la consecución de sus sueños artísticos y la autenticidad. Por otra parte, los comienzos de la relación entre ellos son antirrománticos, pero se vuelve al romanticismo desde que se sienten atraídos hasta que plantean su separación. Así, dentro de la crisis que debe atravesar la pareja protagonista de un melodrama, en la resolución, lejos de un final feliz en el que acaben unidos, se vuelve a un rasgo tan antirromántico como el pragmatismo cuando tienen que decidir el futuro de su relación, algo que hacen en base a sus carreras profesionales. Y todo ello, además, sin cumplir con ninguno de los cinco elementos de la escala de creencias románticas.

El éxito de público y crítica de La La Land señala un posible cambio en el gusto y la sensibilidad de los espectadores actuales que están prefiriendo poco a poco películas que conecten con sus sueños pero que, al mismo tiempo, sean más realistas, actuales y aporten un grado de originalidad; películas en las que exista un componente emocional por medio de la nostalgia, el homenaje o de la reflexión sobre el amor, pero sin excesivas dosis de romanticismo.

Por todo ello, La La Land, dentro de este carácter aglutinador y contradictorio, muestra ser una creación postmoderna. En la reflexión sobre la pureza y la supervivencia del cine, dentro de la cual el jazz es una metáfora, Chazelle, lejos de defender un clasicismo que lo ancle en un punto del pasado, se muestra partidario de una evolución en la que se rescate lo mejor de la historia del cine dentro de un pastiche para, a partir de ahí, buscar elementos de originalidad que, a su vez, pertenezcan al contexto social actual. En esta línea, desde el punto de vista estético, muestra su recelo sobre la idea de que el futuro del cine pueda estar en ciertas aportaciones tecnológicas, puesto que estas harían que el cine perdiese su esencia. Como ocurre con uno de los debates sobre el jazz, Chazelle hace su particular reflexión sobre el rumbo que debe seguir el cine para conservar la autenticidad, la originalidad y la pureza, una búsqueda que tiene mucho de romántica. 


\section{Referencias bibliográficas}

Adamczyk, K. y Metts, S. (2014). The Factor Structure of the Polish-Language Version of the Romantic Beliefs Scale. Psihologijske teme, 23(2), 209222.

Al-Dabbagh, A. (2014). The Anti-Romantic Reaction in Modern(ist) Literary Criticism. Acta Neophilologica, 47(1-2), 55-67.

Álvarez Barrientos, J. (2002). Imagen y representación del artista romántico. Romanticismo 8: Los románticos teorizan sobre sí mismos (pp. 25-32). Bolonia: Il Capitelo del Sole.

Atienza, B. (2009). El loco en el espejo: locura y melancolía en la España de Lope de Vega. Amsterdam: Rodopi.

Austin, J. F. (2013). Proust, Pastiche, and the Postmodern or Why Style Matters. Lewisburg: Bucknell U. P.

Bravo, M. P. (2007). Literary Creation and the Supernatural in English Romanticism. Gist, 1, 138-143.

Brubach, H. (25 de febrero de 2017). Escaping to La La Land, Then and Now. The New York Times. Recuperado en: https://www.nytimes.com/2017/02/25/opinion/sunday/escaping-tola-la-land-then-and-now.html.

Butler, M. (1982). Romantics, Rebels and Reactionaries. Oxford: Oxford U.P.

Chevalier, J. y Gheerbrant, A. (2007). Diccionario de símbolos (trad. Manuel Silvar y Arturo Rodríguez). Barcelona: Herder.

Comellas, M. (1996). ‘iYo quiero ser caribe! iYo quiero ser romántico!' del buen humor del anti-romanticismo. En L. F. Díaz Larios y E. Miralles (eds.), Actas del I Coloquio Del Romanticismo al Realismo (pp. 357370). Barcelona: Universidad de Barcelona.

Dargis, M. (23 de noviembre de 2016). La La Land Makes Musicals Matter Again. The New York Times. Recuperado en: https://www.nytimes.com/2016/11/23/movies/la-la-land-makesmusicals-matter-again.html.

Fisher, L. (2015). The Poet as Phenomenologist: Rilke and the New Poems. Nueva York: Bloomsbury.

Goimard, J. (1976). La rose des genres à Hollywood. Positif, 177, 34-40.

Golding, D. (marzo de 2017). The Dreamers of La La Land. Senses of Cinema, 82. Recuperado en: http://sensesofcinema.com/2017/featurearticles/dreaming-of-la-la-land/\#fn-30066-7.

Gómez Tarín, F. J. (2018). Apocalipsis y melodrama: el tiempo suspendido y la herida final. $L^{\prime}$ Atalante, 25, 41-54.

Jameson, F. (1985). Postmodernism and Consumer Society. En H. Foster (ed.), Postmodern Culture (pp. 111-125). Londres: Pluto Press. 
Hoesterey, I. (2001). Pastiche: Cultural Memory in Art, Film, Literature. Bloomington: Indiana U.P.

Lantz, H., Keyes, J., y Schultz, M. (1975). The American Family in the Preindustrial Period: From Base Lines in History to Change. American Sociological Review, 40(1), 21-36.

Marzal Felici, J. J. (1998). David Wark Griffith. Madrid: Cátedra.

Oliva, J. I. (1996). La música, la literatura, el cine en la encrucijada antirromántica. Cuadernos del Ateneo, 1, 74-77.

Peckham, M. (2007). Toward a Theory of Romanticism. En S. K. Kumar (ed.), British Romantic Poets. Critical Assessments (pp. 1-21). Nueva Delhi: Atlantic.

Ponce Núñez, J. M. (2007). La conciliación entre la vida personal y profesional: un reto para las empresas y los empleados. Empresa $y$ Humanismo X (1), 181-208.

Rodríguez, R. (15 de diciembre de 2016). La La Land Is an Absolute Dream of a Movie - Even if You Don't Like Musicals. Miami Herald. Recuperado

en: https://www.miamiherald.com/entertainment/movies-newsreviews/article121029688.html.

Runko, M. A. y Pritzker, S. R. (Eds.). (1999). Encyclopedia of Creativity, vol. I. San Diego: Academic Press.

Sand, G. (1928). Histoire de ma vie, vol. IV. París: Calmann-Lévy.

Santibáñez, F. (2003). Death and Foreboding in Romeo and Juliet. Estudios Humanísticos Filología, 25, 159-171.

Sprecher, S., y Metts, S. (1989). Development of the 'Romantic Beliefs Scale' and Examination of the Effects of Gender and Gender-Role Orientation. Journal of Social and Personal Relationships, 6(4), 387411.

Stevenson, B. (marzo de 2017). From Los Angeles to La La Land: Mapping Whiteness in the Wake of Cinema. Senses of Cinema, 82. Recuperado en: $\quad$ http://sensesofcinema.com/2017/feature-articles/from-losangeles-to-la-la-land/.

Strinati, D. (2000). An Introduction to Studying Popular Culture. Londres. Routledge.

Tollinchi, E. (1989). Romanticismo y Modernidad, vol. I. Río Piedras: Universidad de Puerto Rico.

Vallins, D. (2000). Coleridge and the Psychology of Romanticism: Feeling and Thought. Londres: Palgrave MacMillan.

Vineberg, S. (2005). High Comedy in American Movies: Class and Humor from the 1920s to the Present. Lanham: Rowman \& Littlefield Publishers. 
Wellbery, D. E. (2012). Romanticism and Modernity: Epistemological Continuities and Discontinuities. En T. Pfau y R. Mitchell (eds.), Romanticism and Modernity (pp. 13-28). Londres: Routledge.

Wu, D. (2015). 30 Great Myths about the Romantics. Chichester: Wiley Blackwell.

\section{Filmografía}

Chazelle, D. (2016). La La Land. Estados Unidos: Summit Entertainment / Gilbert Films / Impostor Pictures / Marc Platt Productions.

Cousins, M. (2011). The Story of Film, episode two 'The Triumph of American Film'. Reino Unido: BIM / Hopscotch Films. 